\title{
Vitamin D status of Year 3 children and supplementation through schools with fortified milk
}

\author{
David Graham ${ }^{1,2, *}$, Geoff Kira ${ }^{3}$, John Conaglen ${ }^{1}$, Stephanie McLennan ${ }^{4}$ and \\ Elaine Rush ${ }^{3}$ \\ 'Waikato Clinical School, Faculty of Medical \& Health Sciences, University of Auckland, Auckland, \\ New Zealand: ${ }^{2}$ Child Health, Waikato Hospital, PO Box 3200, Hamilton, New Zealand: ${ }^{3}$ Institute of \\ Sport and Recreation Research New Zealand, Auckland University of Technology, Auckland, New Zealand: \\ ${ }^{4}$ Sport Waikato, Hamilton, New Zealand
}

Submitted 1 April 2008: Accepted 5 November 2008: First published online 24 December 2008

\begin{abstract}
Objective: To evaluate levels of vitamin $\mathrm{D}_{3}$ and HDL-cholesterol (HDL-C), and the ratio of HDL-C to LDL-cholesterol (LDL-C), in schoolchildren receiving vitamin-Dfortified, fat-depleted, high-Ca milk in schools.

Design: Cross-sectional study of previously randomised schools receiving supplemental milk, compared with a matched control group.

Setting: Low-decile Year 1-6 schools in the Waikato region of New Zealand.

Subjects: Year 3 children from either milk schools or control schools, consenting to blood sampling.

Results: For eighty-nine children receiving supplementary daily milk, vitamin $\mathrm{D}_{3}$ levels were significantly higher than in eighty-three control children matched for age, sex, body composition and ethnicity (mean (SD): 49.6 (15.8) v. 43.8 $(14 \cdot 7) \mathrm{nmol} / \mathrm{l}, P=0 \cdot 011$ ), as were HDL-C levels (mean (SD): $1.47(0.35) v .1 \cdot 35$ $(0 \cdot 29) \mathrm{mmol} / \mathrm{l}, P=0 \cdot 024)$ and HDL-C:LDL-C (median: $0.79 v .0 \cdot 71, P=0.026)$. LDL-C levels were similar in both groups (mean (SD): $2 \cdot 07(0.55) v .2 \cdot 16$ $(0 \cdot 60) \mathrm{mmol} / 1, P=0 \cdot 31)$. Of control children, 32/83 (38.6\%) had vitamin $\mathrm{D}_{3}$ levels below the cut-off for vitamin $\mathrm{D}$ insufficiency $(<37.5 \mathrm{nmol} / \mathrm{l})$, compared with $18 / 89(20 \cdot 2 \%)$ of the milk group (Pearson's $\chi^{2}=7 \cdot 00, P=0 \cdot 008$ ). Mean 25-hydroxyvitamin $\mathrm{D}$ (vitamin $\mathrm{D}_{3}$ ) levels in the milk group were still below the lower end of the recommended normal range $(60 \mathrm{nmol} / \mathrm{l})$.

Conclusions: Vitamin $\mathrm{D}_{3}$ levels are low in low-decile Year 3 children in midwinter. Levels are improved with vitamin-D-fortified milk but still below the recommended range. HDL-C and HDL-C:LDL-C levels are improved in the milk-supplemented group. This supports the supply of vitamin-D-fortified, fat-reduced milk to schools.
\end{abstract}

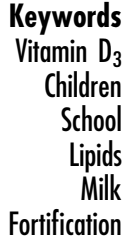

Keywords Vitamin $\mathrm{D}_{3}$ Children

School

Milk

Fortification
Vitamin D has important roles in both the skeleton and non-skeletal tissues. In addition to the role of vitamin D in skeletal metabolism, Holick ${ }^{(1)}$ recently reviewed its potential role in common cancers, autoimmune disease, infectious diseases and CVD. A number of population studies have reported on low levels of vitamin D in the community $^{(2)}$. Vitamin D status has been reported in New Zealand children from a range of ethnic groups ${ }^{(3)}$. The vitamin D levels of children are generally low, with the lowest values in Māori and Pacific children and in obese children. In addition, the levels of vitamin D are lower in girls than in boys and lower in winter than in summer. It is likely that vitamin D deficiency will track into adulthood but longitudinal studies are lacking. Vitamin $\mathrm{D}_{3}$ has been shown to be inversely associated with body fatness across the life cycle ${ }^{(4,5)}$.
One of the challenges of improving vitamin D levels is that vitamin D sources are limited to sunlight exposure, dietary intake and dietary supplements. Natural sources of vitamin D are constrained, as the range of foods containing vitamin D is limited and sunlight exposure is diminishing ${ }^{(6)}$. Exposure to the sun is now regarded as a health risk particularly for skin disorders. In addition, children with darker skin need longer contact with sunlight for effective vitamin D production, and sunlight is further limited in winter ${ }^{(7,8)}$. While it is possible for individuals to take vitamin D supplements, at public health level another option is the fortification of foods with vitamin $\mathrm{D}$. One mechanism to achieve this is through vitamin-D-fortified milk.

In the Waikato region of New Zealand, as part of a through-school nutrition and activity programme known as Project Energize ${ }^{(9)}$, younger children in eleven low-decile 
primary schools received vitamin-D-fortified, fat-depleted, high-Ca milk. This was provided to the original Project Energize programme schools, not to the control schools. From January 2007, the original Project Energize control schools also became programme schools, with the exception that the children in those schools did not receive milk in school, while milk supplementation continued in the original Project Energize programme schools. This created the opportunity to evaluate vitamin D status in two groups of schools, now matched for overall nutrition and activity initiatives, differing only by through-school supplemental milk intake. Given that the milk being provided was low in fat (specifically saturated fat) and high in $\mathrm{Ca}$, this gave additional potential for comparing blood lipid profiles.

The aim of our study was to evaluate levels of 25hydroxyvitamin $\mathrm{D}$ (vitamin $\mathrm{D}_{3}$ ) and HDL-cholesterol (HDL-C), and the ratio of HDL-C to LDL-cholesterol (LDL$\mathrm{C}$ ), in schoolchildren receiving vitamin-D-fortified, fatdepleted, high-Ca milk in schools. Our hypotheses were that: (i) Year 3 schoolchildren in the Project Energize community have low vitamin D levels; (ii) vitamin D levels may be improved by supplementing children's diet with vitamin-D-fortified, Ca-enriched, low-fat milk; and (iii) low-fat milk may have an effect on the levels of cardioprotective HDL-C in this cohort.

\section{Experimental methods}

The candidate study population included eleven lowdecile primary schools involved in Project Energize ${ }^{(9)}$ receiving daily supplementary milk, and eleven decilematched schools not receiving supplementary milk matched with respect to school size, ethnicity, rurality and socio-economic status. Schools were located between latitude $37^{\circ} 34^{\prime} \mathrm{S}$ and $38^{\circ} 22^{\prime} \mathrm{S}$ in the Waikato region of the North Island of New Zealand. For two years prior to the study, Tetrapaks ${ }^{\mathrm{TM}}$ containing $300 \mathrm{ml}$ of unflavoured supplemental milk (Anchor Mega Milk, Table 1) were supplied chilled and free of charge to the schools by Fonterra Brands New Zealand Ltd for consumption by the children every school day. Milk was usually consumed mid-morning, but always by midday. Project Energize field workers monitored compliance directly with school staff on a weekly basis. In many cases milk was drunk in class under direct supervision. Individual student's daily intake was not directly recorded, but class intake of milk was indirectly assessed by monitoring milk returns.

Ethical approval was obtained from the Northern Y Health ethics committee. Where schools agreed to participate, Year 3 children and their parents were approached and offered the opportunity to become involved in the study. Verbal consent was obtained from the children and written informed consent from the parents. Testing occurred in August 2007, which is the end of winter in New Zealand.
Table 1 Nutrient information on the supplied milk (Anchor Mega Milk, $300 \mathrm{ml}$ Tetrapak $^{\mathrm{TM}}$ )

\begin{tabular}{lcc}
\hline Nutrition & & \% of RDI \\
\hline Energy $(\mathrm{kJ})$ & 702 & \\
Protein $(\mathrm{g})$ & $13 \cdot 5$ & \\
Fat - total $(\mathrm{g})$ & 6 & \\
Fat - saturated $(\mathrm{g})$ & $4 \cdot 2$ & \\
Carbohydrates $(\mathrm{g})$ & $14 \cdot 7$ & \\
Sugars $(\mathrm{g})$ & $14 \cdot 7$ & 23 \\
Na $(\mathrm{mg})$ & 135 & 15 \\
Vitamin $\mathrm{A}(\mu \mathrm{g})$ & 165 & 60 \\
Vitamin $\mathrm{D}_{3}(\mu \mathrm{g})$ & $1 \cdot 5$ & \\
Ca $(\mathrm{mg})$ & 480 & \\
\hline
\end{tabular}

RDI, Recommended Daily Intake ${ }^{(16)}$

Ethnicity was self-reported from a constrained list of options, including European, Māori, Pacific Islander, Chinese, Indian or Other. Ethnicity of the four grandparents was also asked with the same options. For analysis with regard to skin pigmentation, we used a binary coding convention, with New Zealand European (all four grandparents European and therefore essentially pale skin) and all others (essentially darker skin).

On a school day at the school between 08.00 and 09.30 hours, children's fasting blood samples were obtained by a trained phlebotomist. Thirty minutes prior to sampling a topical anaesthetic cream (Amethocaine $4 \% \mathrm{w} / \mathrm{w}$; Smith and Nephew, New Zealand) was applied to the antecubital area. Blood drawn into evacuated tubes was immediately placed on ice, for transport to the laboratory. All blood was processed for analysis within $120 \mathrm{~min}$ of sampling and analysed at a single laboratory (Waikato Hospital laboratory), a facility accredited by International Accreditation New Zealand.

Serum 25-hydroxyvitamin D (vitamin $\mathrm{D}_{3}$ ) was determined using a RIA kit (DiaSorin; Immunodiagnostics, St Peters, Australia), referenced to standards and averaged duplicates reported. Total cholesterol (TC), HDL-C and TAG were determined using a homogeneous enzymatic colorimetric system (Modular P800; Roche, Auckland, New Zealand). LDL-C was then derived using the formula: LDL$\mathrm{C}=[\mathrm{TC}-(\mathrm{TAG} / 2 \cdot 2)-\mathrm{HDL}-\mathrm{C}]$. Parathyroid hormone $(\mathrm{PTH})$ was determined using a solid-phase, two-site chemiluminescent assay (Immulite 2000; Siemens, Auckland, New Zealand). Intact PTH levels were analysed only if the vitamin $\mathrm{D}_{3}$ level was less than $60 \mathrm{nmol} / \mathrm{l}$. Height, weight and percentage body fat (by bioimpedance) of the children were measured as previously described ${ }^{(9)}$.

Statistical analyses were performed using the SPSS statistical software package version 14 (SPSS Inc., Chicago, IL, USA). Data were tested for normality and outliers. Blood parameters other than HDL-C:LDL-C ratio were normally distributed. Two-tailed Student's $t$ test (unpaired) was thus generally used to assess differences between males and females and between control and milk schools, and the Mann-Whitney $U$ test was used to assess for differences in HDL-C:LDL-C by treatment. 
Bivariate Pearson correlation analysis was used to assess associations between percentage body fat and vitamin $\mathrm{D}_{3}$. Analysis of covariance (ANCOVA) was used to examine differences in serum vitamin $\mathrm{D}_{3}$ between gender, control and milk schools and by skin colour after adjusting for percentage body fat. Results are presented as means and standard deviations, effect size and 95\% confidence intervals of differences between means. $P<0.05$ was chosen to represent statistical significance.

\section{Results}

Eleven schools were receiving milk, of which ten agreed to participate. From eleven potential control schools matched by school size, ethnicity and rurality, eight agreed to participate. Year 3 children were invited to participate; 118 and 106 children respectively consented to testing, some of whom declined blood testing, were not fasting or for whom blood testing was unsuccessful, leaving eighty-nine children from milk schools and eighty-three children from control schools with blood results for analysis. The measured children were similar in age, sex, ethnicity and body composition parameters (Table 2). Boys had less percentage fat than girls $(P<0 \cdot 0001)$.
The independent $t$ test with equal variances demonstrated that serum vitamin $\mathrm{D}_{3}$ and HDL-C in the milk group were higher (Table 3), but LDL-C, TC and TC:HDL-C ratio were not different from those in the control group. While HDL-C:LDL-C ratio was not normally distributed, the Mann-Whitney $U$ test demonstrated that the ratio was higher in the milk group.

More than $80 \%$ of the children we tested, with more in the control group, had a low vitamin $\mathrm{D}_{3}$ level (mean: $44 \mathrm{nmol} / \mathrm{1})$.

More control children were vitamin D insufficient $(<37 \cdot 5 \mathrm{nmol} / \mathrm{l})$ than milk children (control 32/83 (38.6\%) $v$. milk 18/89 (20.2\%); Pearson's $\left.\chi^{2}=7 \cdot 00, P=0 \cdot 008\right)$. One child in the control group was clearly vitamin D deficient at $13 \mathrm{nmol} / \mathrm{l}$. In the total sample of 172 children, $140(81 \cdot 4 \%)$ were below the lower limit of the reference range for the local laboratory $(60 \mathrm{nmol} / 1)$; seventy-two $(86 \cdot 7 \%)$ controls and sixty-eight $(76 \cdot 4 \%)$ of the milk group $(P=0 \cdot 12)$. Using a vitamin D threshold of $50 \mathrm{nmol} / \mathrm{l}$, sixty $(72 \cdot 3 \%)$ controls and forty-nine $(55 \cdot 1 \%)$ of the milk group were below the threshold $(P=0 \cdot 019)$.

Finally, while we used the National Health and Nutrition Examination Survey criteria for vitamin D deficiency ${ }^{(2)}$, i.e. $<37.5 \mathrm{nmol} / \mathrm{l}$, levels as low as $25 \mathrm{nmol} / 1$ have been used elsewhere ${ }^{(10)}$; applying the latter criterion, seven of the

Table 2 Characteristics of schoolchildren who consented and were fasting: Year 3 children, Waikato region of New Zealand, 2007

\begin{tabular}{|c|c|c|c|c|c|c|}
\hline & \multicolumn{3}{|c|}{$\begin{array}{c}\text { Control group } \\
(n \text { 83) }\end{array}$} & \multicolumn{3}{|c|}{$\begin{array}{l}\text { Milk group } \\
\quad(n \text { 89) }\end{array}$} \\
\hline & Mean & SD & $n$ & Mean & SD & $n$ \\
\hline Age (years) & $7 \cdot 2$ & $0 \cdot 8$ & & $7 \cdot 6$ & 0.9 & \\
\hline Sex: male/female & & & $46 / 37$ & & & $46 / 43$ \\
\hline Ethnicity: E/M/O & & & $13 / 66 / 4$ & & & $13 / 62 / 14$ \\
\hline Weight (kg) & $27 \cdot 7$ & $5 \cdot 8$ & & $29 \cdot 3$ & $6 \cdot 5$ & \\
\hline Height $(\mathrm{cm})$ & $124 \cdot 8$ & $6 \cdot 9$ & & $126 \cdot 5$ & $6 \cdot 4$ & \\
\hline IOTF grade: $-1 / 0 / 1 / 2$ & & & $3 / 52 / 19 / 9$ & & & $1 / 54 / 21 / 13$ \\
\hline Body fat $(\%)$ & $22 \cdot 5$ & $5 \cdot 4$ & & $23 \cdot 5$ & $5 \cdot 9$ & \\
\hline Male & $20 \cdot 8$ & $4 \cdot 1$ & & $21 \cdot 5$ & 4.9 & \\
\hline Female & $24 \cdot 7^{*}$ & $6 \cdot 0$ & & $25 \cdot 6^{*}$ & $5 \cdot 7$ & \\
\hline
\end{tabular}

E/M/O, European/Māori/Other; IOTF, International Obesity Taskforce; grade -1/0/1/2, thin/normal weight/overweight/obese ${ }^{(29)}$.

${ }^{*}$ Significantly different from that of males (independent $t$ test, effect size $0 \cdot 76$ ): $P<0 \cdot 0001$.

Table 3 Fasting blood biochemistry in control and programme schoolchildren: Year 3 children, Waikato region of New Zealand, 2007

\begin{tabular}{|c|c|c|c|c|c|c|c|c|}
\hline & \multicolumn{2}{|c|}{$\begin{array}{l}\text { Control group } \\
\qquad(n 83)\end{array}$} & \multicolumn{2}{|c|}{$\begin{array}{l}\text { Milk group } \\
\quad(n \text { 89) }\end{array}$} & \multirow[b]{2}{*}{ Effect size } & \multicolumn{2}{|c|}{ Difference } & \multirow[b]{2}{*}{$P$ value } \\
\hline & Mean & SD & Mean & SD & & Mean & $95 \% \mathrm{Cl}$ & \\
\hline $\begin{array}{l}\text { Vitamin } \mathrm{D}_{3}(\mathrm{mmol} / \mathrm{l}) \\
\text { TC }(\mathrm{mmol} / \mathrm{l}) \\
\text { HDL-C }(\mathrm{mmol} / \mathrm{l}) \\
\text { LDL-C }(\mathrm{mmol} / \mathrm{l}) \\
\text { TC:HDL-C } \\
\text { TAG }(\mathrm{mmol} / \mathrm{l})\end{array}$ & $\begin{array}{l}43 \cdot 8 \\
3 \cdot 8 \\
1 \cdot 34 \\
2 \cdot 2 \\
2 \cdot 9 \\
0 \cdot 7\end{array}$ & $\begin{array}{l}14 \cdot 8 \\
0 \cdot 6 \\
0 \cdot 29 \\
0 \cdot 6 \\
0 \cdot 7 \\
0.3\end{array}$ & $\begin{array}{l}49 \cdot 6 \\
3 \cdot 9 \\
1 \cdot 47 \\
2 \cdot 1 \\
2 \cdot 8 \\
0 \cdot 8\end{array}$ & $\begin{array}{l}15 \cdot 7 \\
0 \cdot 6 \\
0 \cdot 34 \\
0 \cdot 6 \\
0 \cdot 7 \\
0 \cdot 3\end{array}$ & $\begin{array}{r}-0.38 \\
-0.17 \\
-0.41 \\
0 \cdot 17 \\
0 \cdot 14 \\
-0.33\end{array}$ & $\begin{array}{l}-5 \cdot 8 \\
-0 \cdot 1 \\
-0 \cdot 13 \\
0 \cdot 1 \\
0 \cdot 2 \\
-0 \cdot 1\end{array}$ & $\begin{array}{c}-10 \cdot 8,-1 \cdot 3 \\
-0 \cdot 3,0 \cdot 1 \\
-0 \cdot 22,-0 \cdot 01 \\
-0 \cdot 1,0 \cdot 3 \\
-0 \cdot 0,0 \cdot 4 \\
-0 \cdot 2,0 \cdot 0\end{array}$ & $\begin{array}{l}0 \cdot 01^{\star} \\
0 \cdot 50^{\star} \\
0 \cdot 01^{\star} \\
0 \cdot 30^{\star} \\
0 \cdot 10^{\star} \\
0 \cdot 29^{\star}\end{array}$ \\
\hline TAG $(\mathrm{mmol} / \mathrm{l})$ & Median & IQR & Median & IQR & & & & \\
\hline HDL-C:LDL-C & 0.6 & 8 & 0.7 & 9 & & & & $0.03+$ \\
\hline
\end{tabular}

TC, total cholesterol; HDL-C, HDL cholesterol; LCL-C, LDL cholesterol; IQR, interquartile range.

*Two-tailed independent $t$ test, equal variances.

+Mann-Whitney $U$ test. 
Table 4 Mean serum vitamin $D_{3}$ levels of schoolchildren by sex, treatment and ethnicity: Year 3 children, Waikato region of New Zealand, 2007

\begin{tabular}{|c|c|c|c|c|c|c|}
\hline & \multirow[b]{2}{*}{$n$} & \multicolumn{2}{|c|}{ Vitamin $D_{3}(\mathrm{nmol} / \mathrm{l})$} & \multirow[b]{2}{*}{$F$} & \multirow[b]{2}{*}{ df } & \multirow[b]{2}{*}{$P$} \\
\hline & & Mean & SD & & & \\
\hline \multicolumn{7}{|l|}{ Sex } \\
\hline Male & 92 & 47 & 15 & 0.006 & 1,170 & 0.936 \\
\hline Female & 80 & 47 & 16 & & & \\
\hline \multicolumn{7}{|l|}{ Treatment } \\
\hline Control & 83 & 44 & 14 & $6 \cdot 370$ & 1,170 & 0.013 \\
\hline Milk & 89 & 50 & 16 & & & \\
\hline \multicolumn{7}{|l|}{ Ethnicity } \\
\hline European & 26 & 63 & 15 & $44 \cdot 245$ & 1,170 & $<0.0001$ \\
\hline Non-European & 146 & 44 & 13 & & & \\
\hline
\end{tabular}

control children would be regarded as vitamin D deficient, compared with one of the milk children. Post boc analysis revealed that child, and the five other children with the lowest values for milk schools, to come from a single milk school, where it happened that there were significant compliance issues with drinking milk. This was not an issue with the other milk schools, and for all schools the milk was supplied and maintained chilled. Commentary from some schools did suggest that younger children had difficulties with drinking the full $300 \mathrm{ml}$ volume.

Separately, we explored the relationship between vitamin $\mathrm{D}_{3}$ levels and other parameters. There was no difference between sexes for vitamin $\mathrm{D}_{3}$. There was a negative association between vitamin $\mathrm{D}_{3}$ and percentage body fat adjusted for sex $(r=-0 \cdot 16,95 \%$ CI $-0 \cdot 01,-0 \cdot 30, P=0 \cdot 03)$. Vitamin $\mathrm{D}_{3}$ levels were significantly different between the two skin pigmentation groups, European $v$. Non-European (mean (SD): 63 (15) v. 44 (13) nmol/1, $P<0 \cdot 0001$ ).

Table 4 shows the unadjusted mean vitamin $D_{3}$ levels of Year 3 children by group. The $F$ and $P$ values were derived from ANCOVA after adjusting for body percentage fat. Cell sizes exceeded thirteen for all comparisons and the variance ratio was less than 1:2. There was no difference by sex $(P=0 \cdot 161)$ or interaction of sex with treatment or skin colour, and therefore further analysis excluded this grouping. The difference between marginal means for skin pigmentation (European $v$. other) was $19 \mathrm{nmol} / 1$ (95\% CI 14, 25, $P<0.0001)$. In addition, the difference in marginal means between milk and control schools was $6 \mathrm{nmol} / 1$ (95\% CI 0, 1, $P=0 \cdot 05)$.

PTH was analysed only for children with vitamin $D_{3}$ level below $60 \mathrm{nmol} / \mathrm{l}(n$ 138). Within that constraint, there was a negative association between vitamin $\mathrm{D}_{3}$ levels and PTH levels $(r=-0 \cdot 32,95 \%$ CI $0 \cdot 16,0 \cdot 46, P<0 \cdot 0001$. With an upper limit of PTH set at $6.1 \mathrm{pmol} / \mathrm{l}$, seven children had elevated PTH and their mean 25-hydroxyvitamin D level was $33 \mathrm{nmol} / 1$ (median 33, range $13-51 \mathrm{nmol} / \mathrm{l}$ ).

\section{Discussion}

In our study population mean serum vitamin $\mathrm{D}_{3}$ was low in Year 3 children in low-decile schools in late winter months. Vitamin D levels were not associated with sex but were associated with skin pigmentation, percentage body fat and consumption of vitamin-D-fortified milk. In addition, the milk-supplemented group had a significantly better cardioprotective lipid profile.

Consensus is lacking on the optimal serum levels of vitamin D; however, the Australian and New Zealand position statement ${ }^{(11)}$ and other expert views ${ }^{(12)}$ recommend paediatric and adult levels should be at least $50 \mathrm{nmol} / \mathrm{l}$. Holick, citing other biochemical evidence, argues that relative insufficiency extends to $72 \mathrm{nmol} / \mathrm{l}$, with optimal levels above $75 \mathrm{nmol} / \mathrm{l}$. Vitamin D intoxication has been observed when serum levels are greater than $374 \mathrm{nmol} / \mathrm{l}^{(1)}$.

A number of population studies report low serum levels of vitamin $\mathrm{D}$, including in New Zealand ${ }^{(3,8,13)}$. There is no mandatory fortification of foods with vitamin $D$ in New Zealand and for the few foods allowed fortification, the level is low. Two natural sources of vitamin D in the New Zealand diet are eggs and fish. The National Children's Nutrition Survey ${ }^{(14)}$ reports that only $62 \%$ and $37 \%$ of children eat these foods once weekly or more, so it is likely that dietary intake is low and we know of no reason why intake would differ by treatment or sunlight as the geographical locations were not different. Our data showed that the majority of children (and more so in the control group) had low vitamin $\mathrm{D}_{3}$ levels, and that $38.4 \%$ of the control group had vitamin D insufficiency $(<37 \cdot 5 \mathrm{nmol} / \mathrm{l})$, consistent with previous New Zealand research at a similar time of year ${ }^{(8)}$. If lower vitamin D levels are associated with short- and long-term morbidity, then these data, in common with other studies, demonstrate proof of need.

Vitamin D levels can be maintained through either dietary intake or sun exposure. The Australian New Zealand nutrient reference values for children recommend an Adequate Intake (AI) of $5 \mu \mathrm{g} / \mathrm{d}$ with an upper level of $80 \mu \mathrm{g} / \mathrm{d}^{(15)}$, with a previously published Recommended Daily Intake (RDI) of $10 \mu \mathrm{g} / \mathrm{d}^{(16)}$. A recent review of vitamin D supplementation trials by Hathcock et al. ${ }^{(17)}$ concluded that in healthy adults a vitamin D dose $\geq 250 \mathrm{mg} / \mathrm{d}$ showed no evidence of toxicity, so the risk of over-supplementation is minimal. Optimal measures of vitamin $\mathrm{D}_{3}$ concentration in 
the blood have traditionally been validated by biomarkers of bone mineral density and other measures of bone health. If a level of $75-100 \mathrm{nmol} / 1$ were the target range, then for adults an intake of $25 \mu \mathrm{g} / \mathrm{d}$ may be necessary in no less than $50 \%$ of the population to bring serum vitamin $\mathrm{D}_{3}$ to above $75 \mathrm{nmol} / \mathrm{l}^{(18)}$.

The Australia New Zealand consensus ${ }^{(11)}$ states that 'most healthy children in Australia and New Zealand receive enough sunlight exposure to maintain adequate vitamin D levels', but then states that '[in New Zealand] $50 \%$ of all children [have] serum 25 OHD concentrations less than $50 \mathrm{nmol} / \mathrm{l}$ '. That consensus also reports that while regular sunlight exposure can prevent vitamin D deficiency, the safe exposure time for children is unknown. Controlled sun exposure is one of the standard recommendations for optimising vitamin $\mathrm{D}$ content ${ }^{(19)}$; however, there are conflicting messages related to skin damage and skin cancer risk ${ }^{(20)}$. Sun block also inhibits vitamin $\mathrm{D}_{3}$ synthesis by up to $98 \%{ }^{(19)}$, and paradoxically UVB light, as well as promoting synthesis of dehydrocholesterol to previtamin $\mathrm{D}_{3}$, also breaks down previtamin $\mathrm{D}_{3}$ and vitamin $\mathrm{D}_{3}$ to inactive metabolites ${ }^{(21)}$.

The challenge of obtaining adequate vitamin $\mathrm{D}_{3}$ though sun exposure is greater for darker-skinned people, and this is strongly reinforced by our data and others $^{(22)}$. People with darker skin may need more sun exposure than is practicable, with additional challenges provided by the geographic location, cultural norms and the weather patterns particularly in winter ${ }^{(8,22,23)}$. Both of our study groups were involved in a programme encouraging outdoor activity, but vitamin $\mathrm{D}_{3}$ levels remained low albeit that it was winter. It is also less likely that the parents of children in low-decile schools would ordinarily be aware of the need for or be able to access vitamin D supplementation.

Among the advantages of delivering vitamin $\mathrm{D}$ in Ca-enriched low-fat milk is that vitamin D, after conversion to the active metabolite vitamin $\mathrm{D}_{3}$, will promote $\mathrm{Ca}$ absorption from the gut in preference to mobilising $\mathrm{Ca}$ from bone. An additional benefit for the children receiving milk in our study was an improvement in their cardioprotective lipid profile. Mechanisms by which Ca-enriched milk may promote a long-term change in lipids include an inhibition of the absorption of fat by calcium phosphate, increased binding and excretion of bile acids, and increased lipolysis and fat oxidation ${ }^{(24,25)}$. Vitamin $D_{3}$ levels are inversely related to fatness and children in lower-decile schools tend to have higher rates of overweight and obesity ${ }^{(14)}$. Furthermore, in a similar New Zealand population an increase in percentage body fat and lean mass was shown to be related to increased TC and HDL-C, respectively ${ }^{(26)}$.

Our study has a number of limitations. The design was cross-sectional and baseline blood measurements were not made. An opportunity arose when vitamin-Dfortified, low-fat and high-Ca milk was being supplied to only one of two groups of matched low-decile schools in Project Energize. Our blood sampling was done in late winter, in a predominantly darker-skinned sample. This meant it was unlikely that sun exposure would have a major impact on vitamin $\mathrm{D}_{3}$ levels. While children may have received foods high in vitamin $\mathrm{D}$ in the home environment, vary in their sun exposure or have been receiving vitamin D supplementation, we have no reason to believe that the usual intake of the control and intervention children would vary at home. Neither group had any restriction on the type of milk consumed at home; however, in the New Zealand setting, most commercial milks are not fortified with vitamin D and the fortified milk is sold as a premium product at higher price. Finally, there is no mandatory requirement for fortification with vitamin D in the commercial food industry, and voluntary fortification is largely limited to milk products. In addition, our binary categorisation of skin colour is not a robust measure. A number of children had grandparents of mixed ethnicity - European was classified when all grandparents were of European origin - the other ethnicities would vary in skin colour and therefore potential ability to synthesise vitamin $\mathrm{D}_{3}$.

The milk supplied in the schools included the maximum amount of vitamin D $(1.5 \mu \mathrm{g} / 300 \mathrm{ml})$ allowed by New Zealand food standard 1.3.2. This is $15 \%$ of the current RDI and $30 \%$ of the AI in new Australasian guidelines $^{(15)}$. However, we saw a statistically significant difference in both vitamin $\mathrm{D}_{3}$ levels and vitamin $\mathrm{D}$ insufficiency rates in the two groups, which is likely to be of clinical significance. We believe this demonstrates both proof of concept (in that vitamin-D-fortified milk was able to be supplied and was consumed by schoolchildren) and proof of efficacy (in that there was biochemically demonstrable impact). Separately, consideration should be given to increasing the maximum allowable level of vitamin $\mathrm{D}$ in fortified foods.

To date, there have been no longitudinal studies to determine whether low childhood vitamin D levels are associated with increased risks of morbidity in adults. However, this is biologically plausible given that: (i) low vitamin D levels in childhood causes rickets in younger children and poor bone mineralisation over time; (ii) low vitamin D level in adulthood is associated with a range of morbidities; (iii) there are plausible biological mechanisms for low vitamin D having multi-system cellular effects $^{(27)}$; (iv) the risk factors for low childhood and adult vitamin D levels are similar; and (v) low vitamin D levels are likely to be chronic across the life $\operatorname{span}^{(28)}$.

There are difficulties in improving vitamin D levels using strategies such as: (i) providing vitamin $\mathrm{D}$ as a supplement; (ii) increasing intake of vitamin-D-containing foods; and (iii) ensuring adequate but safe sun exposure. These are all more challenging in economically deprived communities. Provision of vitamin-D-fortified, Ca-enriched, fat-reduced milk in schools appears to be a 
safe and effective means of improving vitamin D levels for school-aged children.

\section{Conclusions}

Vitamin $\mathrm{D}_{3}$ levels were low in low-decile Year 3 schoolchildren in midwinter. Levels were improved with vitaminD-fortified milk, and the proportion of children who had vitamin $\mathrm{D}$ insufficiency was reduced. Mean vitamin $\mathrm{D}_{3}$ levels were still below the recommended normal range. HDL-C levels and HDL-C:LDL-C were improved in the milksupplemented group. This supports the supply of vitamin-Dfortified, Ca-enriched, fat-reduced milk in schools.

\section{Acknowledgements}

The authors are not aware of any conflict of interest. The study was made possible by funding from Waikato Medical Research Foundation, the Waikato District Health Board, and the Health Research Council. D.G., J.C., G.K., S.M. and E.R. all contributed to the study design and writing. D.G. and G.K. undertook the field work. G.K. and E.R. undertook data management. E.R., D.G. and G.K. undertook data analysis.

\section{References}

1. Holick MF (2007) Vitamin D deficiency. N Engl J Med 357, 266-281.

2. Hanley DA \& Davison KS (2005) Vitamin D insufficiency in North America. J Nutr 135, 332-337.

3. Rockell JE, Skeaff CM, Williams SM \& Green TJ (2006) Serum 25-hydroxyvitamin D concentrations of New Zealanders aged 15 years and older. Osteoporos Int 17, 1382-1389.

4. Smotkin-Tangorra M, Purushothaman R, Gupta A, Nejati G, Anhalt H \& Ten S (2007) Prevalence of vitamin D insufficiency in obese children and adolescents. J Pediatr Endocrinol Metab 20, 817-823.

5. Snijder MB, van Dam RM, Visser M, Deeg DJ, Dekker JM, Bouter LM, Seidell JC \& Lips P (2005) Adiposity in relation to vitamin D status and parathyroid hormone levels: a population-based study in older men and women. J Clin Endocrinol Metab 90, 4119-4123.

6. Holick MF (2006) High prevalence of vitamin D inadequacy and implications for health. Mayo Clin Proc 81, 353-373.

7. Kimlin MG, Downs NJ \& Parisi AV (2003) Comparison of human facial UV exposure at high and low latitudes and the potential impact on dermal vitamin D production. Photochem Photobiol Sci 2, 370-375.

8. Rockell JE, Green TJ, Skeaff CM et al. (2005) Season and ethnicity are determinants of serum 25-hydroxyvitamin D concentrations in New Zealand children aged 5-14 y. J Nutr 135, 2602-2608.

9. Graham D, Appleton S, Rush E, McLennan S, Reed P \& Simmons D (2008) Increasing activity and improving nutrition through a schools-based programme: Project Energize. 1. Design, programme, randomisation and evaluation methodology. Public Health Nutr 11, 1076-1084.

10. El-Hajj Fuleihan G, Nabulsi M, Choucair M, Salamoun M, Hajj Shahine C, Kizirian A \& Tannous R (2001) Hypovitaminosis D in healthy schoolchildren. Pediatrics 107, E53.
11. Munns C, Zacharin MR, Rodda CP et al. (2006) Prevention and treatment of infant and childhood vitamin D deficiency in Australia and New Zealand: a consensus statement. Med J Aust 185, 268-272.

12. Cancer Society of New Zealand (2006) Position Statement: The Risks and Benefits of Sun Exposure in New Zealand. Wellington: Cancer Society of New Zealand and the Health Sponsorship Council.

13. Scragg R, Holdaway I, Singh V, Metcalf P, Baker J \& Dryson E (1995) Serum 25-hydroxyvitamin $\mathrm{D}_{3}$ is related to physical activity and ethnicity but not obesity in a multicultural workforce. Aust N Z J Med 25, 218-223.

14. Ministry of Health (2003) NZ Food NZ Children, Key Results of the 2002 National Children's Nutrition Survey. Wellington: Ministry of Health.

15. Commonwealth Department of Health and Ageing, Australia/Ministry of Health, New Zealand/National Health and Medical Research Council, Australia (2005) Nutrient Reference Values for Australia and New Zealand including Recommended Dietary Intakes. Canberra: Commonwealth of Australia and New Zealand Government.

16. National Health and Medical Research Council (1991) Recommended Dietary Intakes for Use in Australia. Canberra: National Health and Medical Research Council.

17. Hathcock JN, Shao A, Vieth R \& Heaney R (2007) Risk assessment for vitamin D. Am J Clin Nutr 85, 6-18.

18. Bischoff-Ferrari HA, Giovannucci E, Willett WC, Dietrich T \& Dawson-Hughes B (2006) Estimation of optimal serum concentrations of 25-hydroxyvitamin D for multiple health outcomes. Am J Clin Nutr 84, 18-28.

19. Holick MF (2004) Sunlight and vitamin D for bone health and prevention of autoimmune diseases, cancers, and cardiovascular disease. Am J Clin Nutr 80, 6 Suppl., 1678S-1688S

20. Moan J, Porojnicu AC, Dahlback A \& Setlow RB (2008) Addressing the health benefits and risks, involving vitamin $\mathrm{D}$ or skin cancer, of increased sun exposure. Proc Natl Acad Sci U S A 105, 668-673.

21. Holick MF (1995) Environmental factors that influence the cutaneous production of vitamin D. Am J Clin Nutr 61, 3 Suppl., 638S-645S.

22. Norman AW (1998) Sunlight, season, skin pigmentation, vitamin $\mathrm{D}$, and 25 -hydroxyvitamin $\mathrm{D}$ : integral components of the vitamin D endocrine system. Am J Clin Nutr 67, 1108-1110.

23. Kimlin MG, Olds WJ \& Moore MR (2007) Location and vitamin D synthesis: is the hypothesis validated by geophysical data? J Photochem Photobiol B 86, 234-239.

24. Lorenzen JK, Nielsen S, Holst JJ, Tetens I, Rehfeld JF \& Astrup A (2007) Effect of dairy calcium or supplementary calcium intake on postprandial fat metabolism, appetite, and subsequent energy intake. Am J Clin Nutr 85, 678-687.

25. Major GC, Alarie F, Dore J, Phouttama S \& Tremblay A (2007) Supplementation with calcium + vitamin D enhances the beneficial effect of weight loss on plasma lipid and lipoprotein concentrations. Am J Clin Nutr 85, 54-59.

26. Rush EC, Scragg R, Schaaf D, Juranovich G \& Plank LD (2008) Indices of fatness and relationships with age, ethnicity and lipids in New Zealand European, Maori and Pacific children. Eur J Clin Nutr (Epublication ahead of print version).

27. Chatterjee M (2001) Vitamin D and genomic stability. Mutat Res 475, 69-87.

28. Ben-Shlomo Y \& Kuh D (2002) A life course approach to chronic disease epidemiology: conceptual models, empirical challenges and interdisciplinary perspectives. Int $J$ Epidemiol 31, 285-293.

29. Cole TJ, Bellizzi MC, Flegal KM \& Dietz WH (2000) Establishing a standard definition for child overweight and obesity worldwide: international survey. BMJ 320, 1240-1243. 